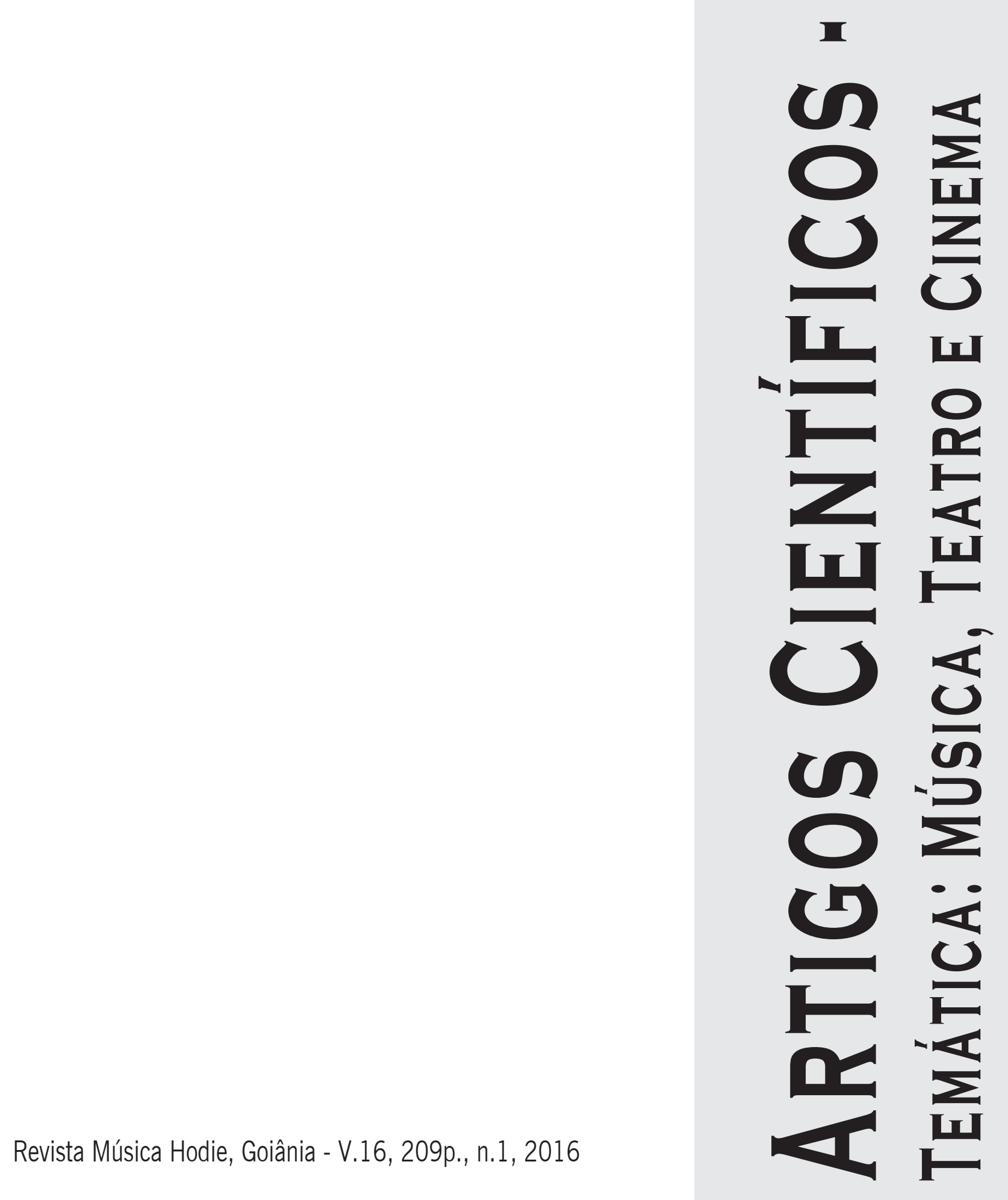




\title{
A autonomia no Teatro Musical: as percepções dos participantes sob a perspectiva da Teoria da Autodeterminação
}

\author{
Flávia Maiara Lima Fagundes (Universidade Federal do Rio Grande do Norte, Natal, RN, Brasil) \\ flaviamaiaralf@gmail.com \\ Giann Mendes Ribeiro (Universidade do Estado do Rio Grande do Norte, Mossoró, RN, Brasil) \\ giannribeiro@gmail.com
}

\begin{abstract}
Resumo: Este estudo tem por temática a motivação no Teatro Musical. A pesquisa teve o objetivo de analisar a satisfação da necessidade psicológica básica de autonomia perceptível pelos integrantes de uma companhia de Teatro Musical, e identificar os tipos de motivação encontrados. Desenvolvida sob a perspectiva da Teoria da Autodeterminação, esta pesquisa teve uma abordagem qualitativa, com base no estudo de entrevistas como estratégia de investigação, tendo a entrevista semiestruturada como principal técnica de coleta de dados. A análise dos dados apontou que múltiplos fatores fortaleceram a motivação autônoma dos indivíduos nas atividades desenvolvidas na Companhia Musicale, e outros fatores comprometeram.

Palavras-chave: Autonomia; Motivação; Teoria da Autodeterminação; Educação musical; Teatro Musical.
\end{abstract}

Autonomy in musical theater: the perceptions of the participants from the perspective of the Theory of SelfDetermination

Abstract: This study is subject to motivation in Musical Theatre. The research aimed to analyze the satisfaction of basic psychological needs for autonomy perceived by members of a musical theater company, and identify the types of found motivation. Developed from the perspective of the theory of self-determination, this research had a qualitative approach, based on the study of interviews and research strategy, with the semi-structured interview as the main data collection technique. Data analysis showed that multiple factors have strengthened the autonomous motivation of individuals in activities at the Company Musicale, and other factors committed.

Keywords: Autonomy; Motivation; Theory of Self-Determination; Musical education; Musical Theater.

La autonomía en el teatro musical: las percepciones de los participantes desde la perspectiva de la Teoría de la Autodeterminación

Resumen: Este estudio está sujeto a la motivación en el teatro musical. La investigación tuvo como objetivo analizar la satisfacción de las necesidades psicológicas básicas para la autonomía percibida por los miembros de una compañía de teatro musical, e identificar los tipos de motivación encontrado. Desarrollado desde la perspectiva de la teoría de la autodeterminación, esta investigación tuvo un enfoque cualitativo, basado en el estudio de las entrevistas y la estrategia de investigación, con la entrevista semiestructurada como la principal técnica de recolección de datos. Análisis de los datos mostró que varios factores han fortalecido la motivación autónoma de los individuos en las actividades de la Sociedad Musical, y otros factores cometido.

Palabras clave: Autonomía. Motivación; Teoría de la Autodeterminación; La educación musical; El Teatro Musical.

\section{Introdução}

Para a fundamentação teórica deste estudo, buscamos contribuições da perspectiva da tradição humanista/organísmica da motivação (REEVE, 2006). Segundo Blasi (1976, apud REEVE, 2006, p. 65), o termo vem da palavra organismo, e se refere a uma entidade viva em estado de incessante troca ativa com o ambiente. Assim, as teorias organísmicas da motivação reconhecem que, como os ambientes mudam continuadamente, logo, os organismos precisam de flexibilização para se ajustar a tais mudanças.

A natureza humana possui diferentes necessidades fundamentais para a vida: as necessidades fisiológicas, as necessidades psicológicas e as necessidades sociais (REEVE, 2006, p. 65). Neste estudo, traremos discussões sobre as necessidades psicológicas como questão primária do referencial teórico fundamentado na Teoria da Autodeterminação.

A Teoria da Autodeterminação (TAD) pressupõe que todos os indivíduos apresentam uma orientação geral, propensões inatas para o crescimento saudável e autorregulação 
para o envolvimento pessoal na busca de satisfazer três necessidades psicológicas básicas: a de autonomia, a de competência e a de pertencimento. Para a TAD essas necessidades refletem diretamente no bom desenvolvimento pessoal e no bem-estar dos indivíduos e estão relacionadas com condições ambientais que favorecem a satisfação das necessidades, pois estas, quando satisfeitas, promovem o bem-estar psicológico (DECI; RYAN, 2008a).

Para alguns autores, há várias situações em que o indivíduo pode estar motivado. Uma pessoa pode estar motivada pelo simples fato de valorizar uma determinada tarefa e/ou atividade, por uma meta de autossuperação no desempenho, por seus próprios interesses, por forças externas, e até mesmo por receio de estar sendo avaliada externamente (RYAN; DECI, 2000a).

Por ser considerada como um fator importante na regulação do comportamento humano, a motivação tem sido tema de muitas discussões (DECI; RYAN, 2000). Na área da Educação Musical, a motivação é imprescindível ao ensino e à aprendizagem. Sobre a motivação do aluno, Guimarães e Boruchovitch (2004) afirmam que um aluno motivado se mostra envolvido e ativo no processo de aprendizagem, e Zenorini e Santos (2010) falam que um aluno desmotivado passa a se desinteressar pelas tarefas propostas, o que pode proporcionar uma queda de qualidade em sua aprendizagem.

Embora o desenvolvimento do campo de estudo da motivação musical tenha se iniciado na segunda metade dos anos 90, alguns pesquisadores revelaram que ainda não existe um grande número de trabalhos na área da Educação Musical no âmbito da Motivação (AUSTIN; RENWICK; MCPHERSON, 2006; HENTSCHKE et al., 2009; 2010). Porém, há um crescente interesse pela temática da motivação nos últimos anos, o que resultou na realização de pesquisas nacionais e internacionais que abordam a aprendizagem musical e a motivação (CERESER; HENTSCHKE, 2009).

A presente pesquisa teve uma abordagem qualitativa, utilizando como estratégia de investigação o estudo de entrevistas, aplicando a entrevista semiestruturada como principal técnica de coleta de dados a 12 participantes de um grupo de Teatro Musical, que por questões éticas, é mencionada pelo pseudônimo de Companhia Musicale - CM. O roteiro das entrevistas foi elaborado com o objetivo de investigar a satisfação das necessidades psicológicas básicas dos participantes nas atividades de montagens de espetáculos musicais e identificar quais os tipos de motivação os levaram a ingressarem e a permanecerem no grupo durante as montagens, tendo por base a Teoria da Autodeterminação para a análise dos dados coletados.

Quadro 1: Estrutura de coleta e identificação dos dados.

\begin{tabular}{|l|l|l|l|}
\hline \multicolumn{1}{|c|}{ Coleta de dados } & \multicolumn{1}{|c|}{ Detalhamento } & \multicolumn{1}{|c|}{ Objetivo/Justificativa } & \multicolumn{1}{|c|}{ Identificação } \\
\hline Entrevistas centra- & Entrevistas semiestrutura- & - Compreender as preferências e as percepções & Pseudônimo - CE, p. 10 \\
lizadas na questão & das com 16 participantes & dos integrantes na realização das atividades na & (CE - Caderno de Entrevistas; \\
de pesquisa & da Companhia Musicale no & Companhia; & p - a página do caderno). \\
& ano de 2014. Os dados fo- & - Investigar as experiências dos alunos e sua mo- & \\
& ram analisados explorando a & tivação no contexto de uma companhia de Teatro & Exemplo: (Beto, CE, p. 2). \\
& percepção de cada indivíduo & Musical e os fatores sociais e contextuais que pu- & \\
& participante. & deram influenciar na motivação. & \\
\hline
\end{tabular}

Os procedimentos de análise foram descritivos e fundamentados na Teoria da Autodeterminação, tendo como categoria de análise a autonomia apresentada pela Teoria das Necessidades Psicológicas Básicas, baseando-se nos tipos de motivações apresentados pela Teoria da Integração Organísmica (RYAN; DECI, 2004; DECI; RYAN, 2008a). 
Quadro 2: Categoria da Satisfação das Necessidades Psicológicas Básicas.

\begin{tabular}{|l|l|}
\hline \multicolumn{1}{|c|}{ Categoria } & \multicolumn{1}{c|}{ Satisfação das necessidades psicológicas básicas } \\
\hline Autonomia & Interesse, preferência, realização em tarefas por sentir prazer e vontade, e tomar decisão se participa \\
- Lócus de Causalidade & ou não de determinadas atividades e apresentações. É sentir origem das próprias ações e não ser ex- \\
- Volição & ternamente comandado. \\
- Escolha Percebida & \\
\hline
\end{tabular}

\section{Referencial teórico}

Tendo a obra de Deci e Ryan, de 1985, como um marco importante em seu delineamento, a Teoria da Autodeterminação - TAD teve início no começo dos anos 70, sendo amplamente estudada por eles entre 1975 e 1991 (VALLERAND, 2001).

Para Reeve (2011, p. 84), "a experiência nos ensina que existem duas maneiras de apreciar uma atividade: de maneira intrínseca ou de maneira extrínseca”. Tentando entender a motivação intrínseca e extrínseca, podemos considerar diversas atividades como participar de um grupo de Teatro Musical, tocar um instrumento ou ler um livro. O que levou uma pessoa a participar de um grupo de Teatro Musical foi que isso significou para ela uma oportunidade de envolver e satisfazer suas necessidades psicológicas. Ela pode fazer Teatro Musical para se divertir, porque gosta, para se exercitar, para cantar, dançar e atuar ao mesmo tempo, para desenvolver habilidades e se sentir livre e autônoma. Porém, ela pode participar do grupo de Teatro Musical por achar que é uma oportunidade de impressionar outras pessoas, de participar de apresentações, de viajar com espetáculos, de ganhar dinheiro e receber prêmios. Assim, "qualquer atividade pode ser abordada tanto segundo uma orientação motivacional intrínseca quanto uma orientação motivacional extrínseca” (REEVE, 2011, p. 84).

As diferenças de orientações motivacionais, para a TAD, resultam da interação entre os ambientes sociais que apoiam ou impedem a propensão inata dos indivíduos ao desenvolvimento saudável e à autorregulação e a própria natureza ativa das pessoas (DECI; RYAN, 2008a; 2008b). A TAD afirma que o ambiente pode satisfazer os recursos internos dos indivíduos, mas também pode frustrar e ignorar os mesmos (DECI; RYAN, 2008b).

A Teoria das Necessidades Psicológicas Básicas parte do pressuposto de que todas as pessoas são movidas por necessidades psicológicas de autonomia, competência e pertencimento. Para a TAD, essas necessidades influenciam no relacionamento saudável e afetivo do indivíduo com o meio ambiente, formando a base para os fatores psicológicos que dão origem à motivação (DECI; RYAN, 2000; RYAN; DECI, 2004). Sendo assim, os acontecimentos ambientais podem promover a motivação autônoma das pessoas, desde que suas necessidades psicológicas sejam apoiadas pelo ambiente.

O comportamento autônomo é o processo de tomada de decisões sobre participarmos ou não de atividades guiado por nossas preferências, vontades e interesses. Quando decidimos o que fazer, queremos que haja flexibilidade e opções para nossa tomada de decisões. Assim, desejamos que nosso comportamento seja conectado com nossos desejos, vontades e preferências. Isso é ter necessidade de autonomia (REEVE, 2011, p. 67).

Nosso comportamento é autônomo quando nossas preferências guiam nossa tomada de decisões sobre participarmos ou não de uma determinada atividade. Essa necessidade possui três qualidades subjetivas: o Lócus da Causalidade Percebido (LCP), que é quando o indivíduo compreende a fonte de suas ações; a Volição, que é a vontade que a pessoa tem de se engajar em alguma atividade com sentimento de liberdade (liberdade psicológica), sem sentimentos de dever ou obrigação; e a Percepção de Haver Escolhido Suas Próprias Ações, 
a escolha percebida, que acontece quando estamos em ambientes que nos fornecem livre escolha nas tomadas de decisão. No entanto, nem todas as escolhas são capazes de promover autonomia. As escolhas que são limitadas às opções oferecidas por outras pessoas não conseguem satisfazer a necessidade de autonomia (REEVE, 2006, 2011).

Considerando a existência dos impactos que acontecimentos externos podem exercer sobre o comportamento humano, a Teoria da Integração Organísmica nos esclarece a forma como os comportamentos extrínsecos podem ser internalizados ou integrados às metas pessoais. Para a TAD a motivação dos indivíduos pode ser explicada através dos diferentes tipos de regulação: a falta de motivação significa que o indivíduo se encontra amotivado, ou seja, a pessoa não está nem intrínseca e nem extrinsecamente motivada; Na regulação Externa (não autodeterminada), o comportamento é controlado por eventos externos como recompensas, ameaças e punições; Na Introjetada (pouco autodeterminada), apesar dos indivíduos já terem o controle interno do seu comportamento, este é determinado por sentimento de dever, culpa ou obrigação; Na regulação Identificada (geralmente autodeterminada), o indivíduo se identifica e atribui importância na tarefa a ser realizada; Na regulação Integrada (autodeterminada), o comportamento apresenta caráter autônomo onde os fatores externos são percebidos e integrados como ações importantes e aceitas como próprias dos indivíduos.

Quadro 3: O continuum de autodeterminação mostrando os tipos de motivação com seus lócus de causalidade e processos correspondentes.

\begin{tabular}{|l|l|l|l|l|l|l|}
\hline \multicolumn{1}{|c|}{ Motivação } & \multicolumn{1}{|c|}{$\begin{array}{c}\text { Falta de } \\
\text { Motivação }\end{array}$} & \multicolumn{4}{c|}{$\begin{array}{l}\text { Motivação } \\
\text { Extrínseca }\end{array}$} & $\begin{array}{c}\text { Motivação } \\
\text { Intrínseca }\end{array}$ \\
\hline $\begin{array}{l}\text { Estilos } \\
\text { Regulatórios }\end{array}$ & $\begin{array}{l}\text { Não } \\
\text { Regulação }\end{array}$ & $\begin{array}{l}\text { Regulação } \\
\text { Externa }\end{array}$ & $\begin{array}{l}\text { Regulação } \\
\text { Introjetada }\end{array}$ & $\begin{array}{l}\text { Regulação } \\
\text { Identificada }\end{array}$ & $\begin{array}{l}\text { Regulação } \\
\text { Integrada }\end{array}$ & $\begin{array}{l}\text { Regulação } \\
\text { Intrínseca }\end{array}$ \\
\hline $\begin{array}{l}\text { Lócus de Causa- } \\
\text { lidade Percebido }\end{array}$ & Impessoal & Externo & Pouco Externa & Pouco Externa & Interno & Interno \\
\hline $\begin{array}{l}\text { Processos Regu- } \\
\text { ladores }\end{array}$ & $\begin{array}{l}\text { Desvalorização, au- } \\
\text { sência de intenção, } \\
\text { falta de controle }\end{array}$ & $\begin{array}{l}\text { Recompensa, } \\
\text { obediência, pu- } \\
\text { nições externas }\end{array}$ & $\begin{array}{l}\text { Envolvimento do } \\
\text { ego, autocontrole, } \\
\text { recompensas e pu- } \\
\text { nições internas }\end{array}$ & $\begin{array}{l}\text { Importância pes- } \\
\text { soal, valorização } \\
\text { consciente }\end{array}$ & $\begin{array}{l}\text { Consciência, con- } \\
\text { cordância, síntese } \\
\text { com o eu (self) }\end{array}$ & $\begin{array}{l}\text { Interesse, pra- } \\
\text { zer, satisfação } \\
\text { inerente }\end{array}$ \\
\hline
\end{tabular}

Fonte: Deci e Ryan (2000).

A miniteoria da Integração Organísmica, prevê que as regulações externas podem passar por um processo de internalização. Portanto, a motivação extrínseca não regulada pode sofrer mudanças e passar à internalização do comportamento autodeterminado. Segundo Reeve, Deci e Ryan (2004), os alunos tendem a internalizar os aspectos sociais e ambientais e normalmente integram os modos de comportamentos ao seu próprio sistema.

\section{A autonomia percebida nas atividades da Companhia Musicale}

No que diz respeito à tomada de decisões em participar da Companhia Musicale, alguns participantes perceberam o Lócus de Causalidade interno, à medida que sentiram em si a origem do desejo em participar das atividades, como mostra o depoimento ${ }^{1}$ abaixo:

Porque eu gosto de música e gosto de teatro, aí eu fiquei sabendo que existia essa companhia. Paguei uma matéria com Davi, ele comentou que participava, aí eu perguntei para ele se eu poderia participar e como era [...] Foi por isso, porque eu me interesso mesmo por música. Eu disse que achava legal e que gostaria de participar. (MARIA, ${ }^{2} \mathrm{CE},{ }^{3}$ p. 7 ) 
Maria não é aluna da Escola de Música da universidade à qual pertence a CM, porém declara gostar muito de música e de teatro e assim buscou maiores esclarecimentos e mostrou-se interessada em participar. Logo, seu Lócus de Causalidade Percebido foi interno, pois ela não declarou ter sido convidada, e sim ter mostrado interesse em participar.

Outros participantes afirmaram ter entrado na companhia porque, além de gostar, possuíam interesses em adquirir experiência profissional (LCP externo). Essas características podem ser representadas pelos depoimentos a seguir:

Participo porque é um lugar onde me sinto bem, consigo cultivar amizades e ao mesmo tempo aprender coisas sobre música, teatro, dança e interpretação, e querendo ou não, também melhorei, como professora e como cantora. No Teatro Musical eu aprendo a melhorar minha presença de palco e minhas expressões, acaba servindo não só para o entretenimento e diversão, como também para o meu lado profissional. Fiquei sabendo do grupo através da professora Marta, quando terminei a licenciatura, ela sempre falava que tinha uma ideia de montar um grupo de Teatro Musical. (GRAÇA, CE, p. 40).

Primeiro, para adquirir experiência de palco. Fiquei sabendo do grupo porque tenho uma amiga que é daqui da escola e ela que me indicou, falou que eu poderia participar. Estou no grupo porque gosto e porque quero adquirir experiência de palco. (SANTIAGO, CE, p. 1)

Estes e outros participantes declararam participar da CM porque gostam, porém, a vontade de participar não se resume apenas ao prazer nas atividades do grupo em si, pois mostram interesse em adquirir experiência para atuar em outras atividades profissionais. Alguns ficaram sabendo da existência do grupo através de amigos e da professora Marta, coordenadora do grupo, e Santiago foi indicado por uma amiga. Esses participantes decidiram ingressar no grupo de Teatro Musical por vontade própria. Porém, o que podemos perceber através de seus depoimentos, é que apesar de inicialmente reafirmarem o interesse em participar do grupo, há uma percepção dos participantes de que suas escolhas para participar da companhia sofreram influências de uma fonte ambiental (LCP externo).

O interesse principal desses participantes caracterizou-se na busca de melhoria da prática de ensino, na contribuição que o grupo pode trazer para a formação profissional e em adquirir experiência de palco. Podemos perceber que a ação é movida por interesses externos. Para Reeve (2006) nem todas as atividades humanas são motivadas intrinsecamente, pelo contrário, grande parte das atividades é influenciada por fatores externos. Os depoimentos revelam que esses participantes perceberam uma valorização pessoal relacionada à realização das atividades, como também um certo grau de internalização, mesmo que o interesse dos envolvidos em ingressar na companhia tenha se originado a partir de fontes externas (LCP externo).

Os participantes atribuíram importância e valor ao reconhecer contribuições profissionais e desenvolvimento de habilidades, proporcionando assim um desejo de querer se aprofundar e adquirir cada vez mais novas experiências. Isso demonstra que houve um processo de internalização e que ocorreu uma adoção de uma determinada importância ou valor. Portanto, a percepção dos comportamentos se deu por motivação extrínseca identificada, pois os participantes articulam importância, utilização pessoal e mostraram razões pelas quais valia a pena realizar as atividades, reconhecendo assim um esforço para adquirir novas habilidades, novos conhecimentos e crescimento profissional (REEVE, 2011).

Quanto à volição e a escolha percebida, o sentimento de liberdade experimentado pelo comportamento autônomo é evidenciado quando um indivíduo sente vontade de se engajar em atividades, sem que seja pressionado por fatores externos. Quando os participantes foram questionados quanto à liberdade em direcionar algumas atividades nos encontros e 
ensaios do grupo, houve percepções bastante diversificadas. Alguns perceberam ter liberdade em direcionar atividades diversas. Teobaldo (CE, p. 110) afirma: "Sim, sim. Fiz alguns exercícios de respiração, aquecimento e algumas partes de técnica vocal [...]”.

Outros participantes declaram não terem sentido liberdade inicialmente, por diferentes motivos:

No começo não, mas já finalizando, antes de entrarmos de férias, tive um pouco, mas não total. Acho que porque já tinham pessoas que exercessem essa função, então eu não tinha tanta liberdade para poder liderar, ficava mais nas escondidas. Mas direcionei algumas atividades. (LETÍCIA, CE, p. 33)

No começo não, porque eu sou muito tímido, mas com tempo eu consegui expressar minha opinião, porque eu demoro a chegar assim e me abrir e falar... É uma dificuldade minha, sou meio fechado mesmo. O grupo tem essa abertura para gente levar uma atividade, mas é porque sou tímido. (JHON, CE, p. 5)

Não. Não é que eu não me sentia à vontade, na verdade eu acho que eu poderia colaborar mais, contribuir mais, tentar fazer dinâmicas com as pessoas. Só que por algum motivo, eu não consigo tomar essa atitude, diferente de como eu faço em outras faixas etárias, ou com outras pessoas. Eu não sei se é o grupo em si, ou se eu me sinto inibida por serem pessoas de mesma faixa etária que eu, adultos... Não sei, tenho algum bloqueio, não entendo [...] Em relação à montagem do espetáculo eu cheguei a sugerir algumas coisas, como, por exemplo, coreografia... De certa forma eu tentei contribuir e deu certo, mas não vou dizer que me sinto à vontade, a liberdade para fazer essas coisas... Não que não exista no grupo, existe sim, é algo mesmo de mim, não sei explicar. (FLOR, CE, p. 14)

Em seus depoimentos, estes participantes demonstram diferentes situações que se tornam impedimentos quanto à liberdade em realizar as tarefas e dar sugestões para as atividades. Os respondentes expuseram suas dificuldades, e a partir delas podemos perceber expressões de inibição, timidez e insegurança, que podem ser entendidos como formas de pressão interna. Consideramos, então, que estas são características de comportamentos que podem prejudicar a motivação autônoma dos participantes, pois, para que a motivação autônoma ocorra, deverá existir baixa pressão, além da concordância pessoal e da alta flexibilidade em sua execução (REEVE; DECI; RYAN, 2004; BZUNECK; GUIMARÃES, 2010, p. 47-48). No entanto, mesmo os respondentes afirmando a existência dessas dificuldades, reconhecem que com o passar do tempo conseguiram superar alguns obstáculos, mesmo que parcialmente.

Outros participantes declaram não haver sentido a liberdade psicológica para realizar as atividades durante os encontros, ensaios e/ou apresentações no período desta pesquisa, sobretudo na montagem de um dos espetáculos:

É... No caso, assumi um compromisso com o grupo, eu não acho legal assumir e chegar na hora e não fazer. Se eu assumi, então vamos fazer, mesmo que não esteja do meu agrado, como não estava, mas vou fazer até o final, vou reclamar às vezes, mas vou fazer até o final. E aí tinha que fazer, tinha que cantar, tinha que estar lá [...]. (MARINA, CE, p. 29)

A fala desta e de outros participantes são marcadas pelo sentimento de dever e obrigação. Fica evidente que participaram de algumas atividades para evitar o sentimento de culpa, caso decidissem abandonar o grupo. Essas são fortes características da regulação introjetada, que implica mais em obedecer do que em aceitar por si próprio as demandas feitas por outros sobre uma determinada maneira de sentir, pensar e se comportar (REEVE, 2011). 
Os depoimentos dos participantes demonstram diferentes aspectos que podem ser considerados como pressão interna: ansiedade, insegurança, medo e nervosismo. $\mathrm{O}$ ambiente que promove autonomia deve incentivar as pessoas na busca de seus próprios objetivos, na escolha de um jeito próprio de resolver seus problemas, de buscar seus interesses e na direção de seus próprios comportamentos (REEVE, 2011).

\section{Considerações finais}

A análise dos dados da necessidade de autonomia dos participantes que colaboraram com este estudo indica que ocorreram múltiplos fatores que fortaleceram a motivação autônoma para os indivíduos participarem da Companhia Musicale. Alguns integrantes perceberam que o comportamento intencional teve origem e regulação pessoal (CHARMS, 1984) e que não foram controlados externamente.

Dos entrevistados que inicialmente mostraram LCP externo, pudemos perceber que, ao se engajarem nas atividades por livre escolha, sentiram vontade de continuar nas atividades do grupo. Portanto, nem todos os participantes estavam intrinsecamente motivados, no entanto, percebemos que houve uma internalização das regulações do comportamento autônomo dos envolvidos que inicialmente apresentaram LPC externo (mais controlado) e uma maior internalização nos alunos que já apresentavam LCP interno (autônomo).

Os fatores que prejudicaram a percepção da autonomia foram: a cobrança pessoal, a sensação de responsabilidade e o sentimento de dever e obrigação, que são características da motivação extrínseca por regulação introjetada. No entanto, pudemos perceber que os integrantes com maior desempenho nas atividades do grupo foram os que internalizaram a importância e o valor das atividades. Estes foram motivados extrinsecamente por regulação identificada (autodeterminada). Confira o quadro a seguir

Quadro 4: Síntese da análise dos dados.

\begin{tabular}{|c|c|c|c|}
\hline $\begin{array}{c}\text { Total de } 12 \\
\text { participantes }\end{array}$ & $\begin{array}{c}\text { Lócus de } \\
\text { Causalidade Percebido }\end{array}$ & $\begin{array}{l}\text { Processos } \\
\text { Reguladores }\end{array}$ & Resultado \\
\hline 06 & $\begin{array}{l}\text { Santiago, Flor, Letícia, Davi, Graça e Lour- } \\
\text { des inicialmente apresentaram caracterís- } \\
\text { ticas da motivação externa por regulação } \\
\text { introjetada, com Lócus de Causalidade } \\
\text { Percebido Externo. } \\
\text { Estes perceberam que o comportamen- } \\
\text { to intencional teve influência do ambiente } \\
\text { controlados externamente. }\end{array}$ & $\begin{array}{l}\text { No decorrer das atividades os participantes } \\
\text { passaram por internalização do comportamen- } \\
\text { to, dependendo das condições situacionais. } \\
\text { Esses participantes foram, inicialmente, in- } \\
\text { fluenciados pelo ambiente e, só após terem } \\
\text { iniciado as atividades, se identificaram e per- } \\
\text { ceberam o interesse em continuar. }\end{array}$ & $\begin{array}{l}\text { Processo multifacetado, } \\
\text { pois os participantes foram } \\
\text { orientados por diferentes ti- } \\
\text { pos de motivação (regula- } \\
\text { ção introjetada e identifi- } \\
\text { cada). }\end{array}$ \\
\hline 06 & $\begin{array}{l}\text { Maria, Teobaldo, Marina, Jhon, Beto e } \\
\text { Amelie apresentaram características da } \\
\text { motivação externa por regulação identifi- } \\
\text { cada, com Lócus de Causalidade Percebi- } \\
\text { do interno, geralmente autodeterminado. } \\
\text { Estes integrantes perceberam que o com- } \\
\text { portamento intencional teve origem e regu- } \\
\text { lação pessoal (CHARMS, 1984) e que não } \\
\text { foram controlados externamente. }\end{array}$ & $\begin{array}{l}\text { No decorrer das atividades os participantes in- } \\
\text { ternalizaram ainda mais os comportamentos } \\
\text { conforme as condições situacionais. }\end{array}$ & $\begin{array}{l}\text { Os integrantes com maior } \\
\text { desempenho nas ativida- } \\
\text { des do grupo foram os que } \\
\text { internalizaram a importân- } \\
\text { cia e o valor das atividades. }\end{array}$ \\
\hline
\end{tabular}

A motivação para participar da Companhia Musicale foi considerada complexa, pois em alguns casos os fatores ambientais promoveram a motivação autônoma, e em ou- 
tros, os fatores comprometeram. Com a análise dos dados, pudemos perceber um processo multifacetado, pois os participantes foram orientados por diferentes tipos de motivação (regulação introjetada e identificada), que passaram por internalização do comportamento dependendo das condições situacionais.

Consideramos relevantes as pesquisas sobre motivação na área da Educação Musical no Brasil e destacamos a importância de se aprofundar na temática, pois pode contribuir para um maior envolvimento dos participantes nas tarefas, maior promoção da autonomia e altos níveis de ensino e aprendizagem musical. Esperamos que os dados deste estudo proporcionem reflexões, para que educadores musicais, professores, regentes, coordenadores de grupos de Teatro Musical e grupos artísticos em geral, possam perceber a importância da promoção da motivação autônoma dos indivíduos em sua formação, seja em contextos de salas de aula, no cenário da educação básica, no âmbito acadêmico ou nos ensaios de grupos musicais em geral.

\section{Notas}

1 Esse depoimento foi gerado a partir da seguinte questão: Por que você participa do grupo de Teatro Musical da Escola de Música?

2 Maria e todos os nomes pessoais citados nesta pesquisa são pseudônimos.

3 CE significa Caderno de Entrevistas, o caderno criado para a transcrição dos dados coletados.

\section{Referências}

AUSTIN, James R.; RENWICK, James; McPHERSON, Gary E. Developing motivation. In: McPHERSON, G. E. (Ed.). The child as musician: a handbook of musical development. Oxford: Oxford University Press, 2006. p. 213-238.

BZUNECK, José Aloyseo; GUIMARÃES, Sueli Édi Rufini. A promoção da autonomia como estratégia motivacional na escola: uma análise teórica e empírica. In: BORUCHOVITCH, Evely; BZUNECK, José Aloyseo; GUIMARÃES, Sueli Édi Rufini (Org.). Motivação para aprender: aplicações no contexto educativo. 2. ed. Petrópolis: Editora Vozes, 2010. Cap. 3. p. 43-70.

CERESER, Cristina Mie Ito; HENTSCHKE Liane. As crenças de autoeficácia: uma perspectiva sociocognitiva da motivação do professor de música. In Anais... CONGRESSO DA ASSOCIAÇÃO NACIONAL DE PESQUISA E PÓS-GRADUAÇÃO EM MÚSICA, 19., 2009, Curitiba, Paraná.

deCHARMS, Richard. Motivation enhancement in educational settings. In: AMES, C., AMES, R. (Ed.). Research on Motivation in Education, Student Motivation. New York: Academic Press, v. 1, p. 275-310, 1984.

DECI, Edward L.; RYAN, Richard M. Facilitating optimal motivation and psychological well-being across lifes's domains. Canadian Psychology, v. 49, n. 1, p. 4-23, 2008 a.

DECI, Edward L.; RYAN, Richard M. Intrinsic motivation and self-determination in human behavior. New York: Plennum Press, 1985.

DECI, Edward L.; RYAN, Richard M. Self-determination theory: a macrotheory of human motivation, development, and health. Canadian Psychology, v. 49, n. 3, p. 182-185, 2008b.

DECI, Edward L.; RYAN, Richard M. The "what" and "why” of goal pursuits: human need and the self-determination of behavior. Psychological Inquiry, v. 11, n. 4, p. 227-268, 2000. 
GUIMARÃES, Sueli Édi Rufini; BORUCHOVITCH, Evely. O estilo motivacional do professor e a motivação intrínseca dos estudantes: uma perspectiva da Teoria da Autodeterminação. Psicologia Reflexão e Crítica, Rio Grande do Sul, v. 17, n. 2, p. 143-150, 2004.

HENTSCHKE, Liane. et al. Motivação para aprender música em espaços escolares e não escolares. Educação Temática Digital (etd), Campinas, v. 10, n. esp., p. 85-104, out. 2009.

HENTSCHKE, Liane. et al. Students' motivacion to study music: the Brazilian context. Research Studies In Music Education, Campinas, v. 2, n. 32, p. 139-154, 2010.

REEVE, Johnmarsholl. Motivação e Emoção. Rio de Janeiro: LCT, 2006.

REEVE, Johnmarshall. Motivação e Emoção. 4. ed. Rio de Janeiro: LCT, 2011. 356 p. Tradução de Luis Antônio Fajardo Pontes e Stella Machado; Revisão técnica de: Maurício Canton Bastos e Nei Gonçalves Calvano.

REEVE, Johnmarsholl; DECI, Edward L.; RYAN, Richard M. Self-determination theory: a dialectical framework for understanding sociocultural influences on student motivation. In: McINERNEY, D. M.; VAN ETTEN, S. (Ed.). Big theories revisited. Greenwich: Information Age Publishing, 2004, p. 31-58.

RYAN, Richard M.; DECI, Edward L. An overview of self-determination theory: an organismic dialectic perspective. In: DECI, Edward L.; RYAN, Edward M. (Ed.). Handbook of self-determination research. Rochester: The University of Rochester Press, 2004.

RYAN, Richard M.; DECI, Edward L. Intrinsic and extrinsic motivations: classic definitions and new directions. Contemporary Educational Psychology, v. 25, n. 1, p. 54-67, 2000a.

VALLERAND, Robert J. A hierarchical model of intrinsic and extrinsic motivation in sport and exercise. In: ROBERTS, C. Glyn. Advances in motivation in sport and exercise. Champaign: Human Kinetcs, 2001. p. 263-319.

ZENORINI, Rita da Penha Campos; SANTOS, Acácia Aparecida Angeli dos. Teoria de Metas de Realização: fundamentos e avaliação. In: BORUCHOVITCH, Evely; BZUNECK, José Aloyseo; GUIMARÃ̃ES, Sueli Édi Rufini (Org.). Motivação para aprender: aplicações no contexto educativo. Petrópolis, RJ: Vozes, 2010. p. 99-125.

Flávia Maiara Lima Fagundes - Mestre em Educação Musical pelo Programa de Pós-Graduação em Música da Universidade Federal do Rio Grande do Norte - UFRN, e licenciada em Música pela Universidade do Estado do Rio Grande do Norte (2013). Atuou como professora de música do Núcleo de Educação da Infância - NEI/CAp - UFRN (2014- 2015). Preparadora vocal da Cia Pão Doce de Teatro. Tem experiência na área de Artes, com ênfase em Música e Teatro, atuando principalmente nos seguintes temas: educação musical e motivação.

Giann Mendes Ribeiro - Doutor em Educação Musical pela Universidade Federal do Rio Grande do Sul. Professor Artes/Música do IFRN. Professor Adjunto IV da UERN. Mestre em etnomusicologia pela Universidade Federal da Paraíba, especialista em Metodologia do ensino de Artes pela Universidade Estadual do Ceará (2002). Possui graduação em Licenciatura Plena em Música pela UECE (1999). Tem experiência em ensino de música, com ênfase em pedagogia do instrumento, Educação Musical, Ensino Coletivo de instrumento, Ensino a Distância e Tecnologias Digitais aplicadas a Educação Musical. A partir do segundo semestre de 2014, o professor Giann Ribeiro desenvolveu um projeto de pesquisa em Desenvolvimento de Tecnologias Inovativas em Educação Musical e uma capacitação com bolsa de desenvolvimento tecnológico e inovação SETEC/MEC e CNPq na Universidade de Ciências Aplicadas de Tampere/Finlândia. Atualmente é professor do Programa de Pós-Graduação em Ensino- POSENSINO da associação ampla UERN/UFERSA/IFRN atuando na linha de ensino de música. 